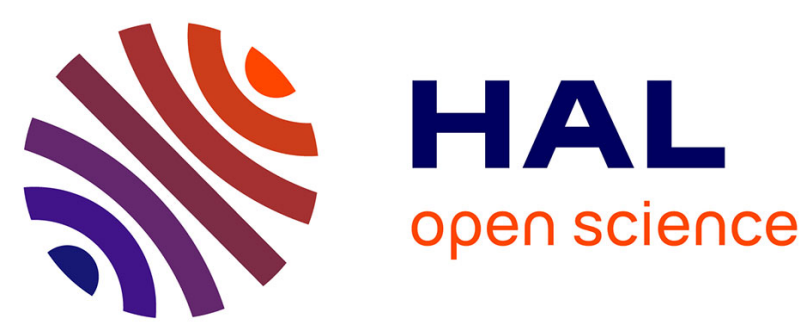

\title{
Porous WS 2 and W 2 N powders by hard templating with colloidal silica
}

P. Gibot, J. Parmentier, Laurent Vidal, F. Schnell, H. Nouali, D. Spitzer

\section{To cite this version:}

P. Gibot, J. Parmentier, Laurent Vidal, F. Schnell, H. Nouali, et al.. Porous WS 2 and W 2 N powders by hard templating with colloidal silica. Ceramics International, 2017, 43 (1), pp.1443-1448. 10.1016/j.ceramint.2016.10.111 . hal-02348745

\section{HAL Id: hal-02348745 \\ https://hal.science/hal-02348745}

Submitted on 31 Jan 2022

HAL is a multi-disciplinary open access archive for the deposit and dissemination of scientific research documents, whether they are published or not. The documents may come from teaching and research institutions in France or abroad, or from public or private research centers.
L'archive ouverte pluridisciplinaire HAL, est destinée au dépôt et à la diffusion de documents scientifiques de niveau recherche, publiés ou non, émanant des établissements d'enseignement et de recherche français ou étrangers, des laboratoires publics ou privés. 
International

Elsevier Editorial System(tm) for Ceramics

Manuscript Draft

Manuscript Number: CERI-D-16-05214R3

Title: Porous WS2 and W2N powders by hard templating with colloidal silica

Article Type: Full length article

Keywords: Tungsten disulfide; Tungsten nitride; Surface properties; Colloidal silica; Hard-Template.

Corresponding Author: Dr. Pierre GIBOT,

Corresponding Author's Institution:

First Author: Pierre GIBOT

Order of Authors: Pierre GIBOT; Julien PARMENTIER; Loic VIDAL; Fabien SCHNELL; Habiba NOUALI; Denis SPITZER

Abstract: Meso- and macroporous tungsten disulfide (WS2) and tungsten nitride (W2N) powders materials were successfully synthesized by reduction of [WO3/colloidal silica] composites under hydrogen sulfide and ammonia gases respectively. The colloidal silica, marketed as Ludox®, was used as a hard template and its removal from the composite led to a porosity release. The products were characterized by X-ray diffraction, nitrogen adsorption, mercury porosimetry and electron microscopy. Wellcrystallized samples with specific surfaces areas close to 40 m2.9-1 were thus synthesized. The present approach might be easily extended to the synthesis of other nitrides and sulfides materials. 


\title{
Porous $\mathrm{WS}_{2}$ and $\mathrm{W}_{2} \mathrm{~N}$ powders by hard templating with colloidal silica
}

\author{
P. Gibot ${ }^{1}$, J. Parmentier ${ }^{2}$, L. Vidal ${ }^{2}$, F. Schnell ${ }^{1}$, H. Nouali ${ }^{2}$, D. Spitzer ${ }^{1}$ \\ 1. Laboratoire des Nanomatériaux pour Systèmes Sous Sollicitations Extrêmes (NS3E), \\ CNRS/ISL/UNISTRA UMR 3208, Institut franco-allemand de recherches de Saint-Louis (ISL), \\ 5 rue du Général Cassagnou, BP 70034, 68301 Saint-Louis, France \\ 2. Institut de Science des Matériaux de Mulhouse (IS2M), CNRS UMR 7361, \\ Université de Strasbourg, Université de Haute-Alsace (UHA), 15 rue J. Starcky, BP2488, 68057 \\ Mulhouse, France
}

Type of article: Research paper.

*Corresponding author. Tel: +33 (0)3.89.69.58.77. E-mail: pierre.gibot@isl.eu (Pierre Gibot)

Co-authors:

julien.parmentier@uha.fr ; Tel.: +33 (0)3.89.60.87.02

loic.vidal@uha.fr ; Tel.: +33 (0)3.89.60.87.37

fabien.schnell@isl.eu ; Tel.: +33 (0)3.89.69.51.70

habiba.nouali@uha.fr; Tel.: +33 (0)3.89.33.67.41

denis.spitzer@isl.eu ; Tel.: +33 (0)3.89.69.50.75 


\begin{abstract}
Meso- and macroporous tungsten disulfide $\left(\mathrm{WS}_{2}\right)$ and tungsten nitride $\left(\mathrm{W}_{2} \mathrm{~N}\right)$ powders were successfully synthesized by reduction of $\left[\mathrm{WO}_{3} /\right.$ colloidal silica] composites under hydrogen sulfide and ammonia gases respectively. The colloidal silica, marketed as Ludox ${ }^{\circledR}$, was used as a hard template and its removal from the composite led to a porosity release. The products were characterized by Xray diffraction, nitrogen adsorption, mercury porosimetry and electron microscopy. Well-crystallized samples with specific surfaces areas close to $\sim 40 \mathrm{~m}^{2} \cdot \mathrm{g}^{-1}$ were thus synthesized. The present approach might be easily extended to the synthesis of other nitrides and sulfides materials.
\end{abstract}

Keywords: Tungsten disulfide; Tungsten nitride; Surface properties; Colloidal silica; Hard-Template. 


\section{Introduction}

Transition metal-based materials exhibit vast and interesting physico-chemical properties (mechanical, electrical, optical, electrochemical, magnetic) covering a large number of proved or suggested applications in diverse domains [1]. Among these compounds, the tungsten-based materials have attracted much attention nowadays in particular when tungsten atoms are associated to non-metallic species such as the pnictogenides (group 15) or the chalcogenides (group 16) of the periodic table of the elements. Among these compounds, the most known and investigated ones are tungsten nitride and tungsten disulfide noted $\mathrm{W}_{2} \mathrm{~N}$ and $\mathrm{WS}_{2}$, respectively. These compounds have common unique properties as for instance a chemical inertia toward alkali and acid environments, a high thermal stability (high melting and boiling points) and interesting electronic properties (semi-conductor for $\mathrm{WS}_{2}$ and conductor for $\mathrm{W}_{2} \mathrm{~N}$ ) [2]. The tungsten nitride offers a high strength and hardness whereas the tungsten disulfide shows lubricating properties related to its layered structure [2,3]. Their competitive electrical and ionic conductivities compared to some current electrode materials make them serious candidates for the development of advanced energy storage systems and fuel cells [4-6]. It has also been mentioned that these two tungsten-based inorganic materials would be attractive solutions in catalysis, in substitution of noble metal catalysts (e.g. Pt), for instance in hydrogenation and dehydrogenation reactions, hydrodesulphurization of crude oil and NO dissociation [7-9]. The performance of the materials used or considered for such applications are greatly dependant of wellspecific criteria such as morphology $(0-3 \mathrm{D})$, nanostructuring and surface properties. From these considerations, authors have conducted works for attempting to reach the synthesis of nanostructured tungsten nitride and tungsten disulfide developing specific design such as high specific surfaces areas with controlled porosities for optimized performances toward the above-mentioned applications.

From the literature, syntheses of $\mathrm{W}_{2} \mathrm{~N}$ and $\mathrm{WS}_{2}$ materials were early focussed on thin films preparation. For that, authors implemented different methods such as chemical vapour deposition (CVD) $[10,11]$ for both tungsten-based materials, atomic layer deposition (ALD) and plasmaenhanced chemical vapour deposition (PECVD) for the tungsten nitride films [10] and laser ablation for the tungsten disulfide preparation [12]. Regarding bulk $\mathrm{W}_{2} \mathrm{~N}$ and $\mathrm{WS}_{2}$, two approaches were developed in the literature based (or not) on the use of a template. The absence of a template, oxide- 
to-nitride (nitridation) and oxide-to-sulfide (sulfidation) processes can be operated from nitrogen- and sulphur-containing reagents (e.g.: carbamide $\left(\left(\mathrm{NH}_{2}\right)_{2} \mathrm{CO}\right)$, thiocarbamide $\left(\left(\mathrm{NH}_{2}\right)_{2} \mathrm{CS}\right)$ and pure sulphur) mixed with various tungsten precursors $\left(\mathrm{WO}_{3}, \mathrm{WO}_{2.72}, \mathrm{H}_{2} \mathrm{WO}_{4}, \mathrm{WCl}_{4},\left(\mathrm{NH}_{4}\right)_{6} \mathrm{~W}_{7} \mathrm{O}_{24} \cdot 4 \mathrm{H}_{2} \mathrm{O}\right)$ to produce nanostructured $\mathrm{W}_{2} \mathrm{~N}$ [13] and $\mathrm{WS}_{2}$ [14-17] materials, respectively. Others authors substituted solid reactants containing nitrogen and sulfur by gaseous reagents such as ammonia $\left(\mathrm{NH}_{3}\right)$ and hydrogen sulfide $\left(\mathrm{H}_{2} \mathrm{~S}\right)$, respectively, for an enhancement of the interfacial reactivity between the components [18-24]. With the use of a hard-template that is supposed to control the size and shape of the porosity, the fabrication of tailored tungsten-based inorganic compounds were performed by means of silica mesoporous templates (SBA-15, KIT-6), as nanostructurated host materials, infiltrated by diverse tungsten precursors such as phosphotungstic acid $\left(\mathrm{PTA}, \mathrm{H}_{3} \mathrm{PW}_{12} \mathrm{O}_{40} \cdot \mathrm{xH}_{2} \mathrm{O}\right)$ and ammonium metatungstate (AMT, $\left(\mathrm{NH}_{4}\right)_{6}\left(\mathrm{H}_{2} \mathrm{~W}_{12} \mathrm{O}_{40}\right) \cdot \mathrm{xH}_{2} \mathrm{O}$ ) and then exposed to $\mathrm{H}_{2} \mathrm{~S}$ and $\mathrm{NH}_{3}$ gaseous environments for the preparation of $3 \mathrm{D}$-mesoporous $\mathrm{WS}_{2}[6,25]$ and $\mathrm{W}_{2} \mathrm{~N}$ [26] materials (after template removal), respectively. As expected, this last approach leads to the fabrication of promising highly ordered mesoporous tungsten nitride and suphide materials, with among the highest specific surfaces areas and best controlled pore sizes ever reported. Nevertheless, this multi-steps synthesis (silica template synthesis, impregnation/calcination stages with the metal precursor repeated at least twice, template leaching...) is time-consuming (> week) and generally yields to limited amount of materials. To limit these drawbacks, cheap and marketed silica hard template obtained from an evaporated colloidal silica solution is an alternative route for synthesizing tailored ceramics as recently demonstrated in the literature [27-30].

Here we describe a simple method for synthesizing significant surface areas $\mathrm{W}_{2} \mathrm{~N}$ and $\mathrm{WS}_{2}$ materials involving the use of hydrated phosphotungstic acid and commercial colloidal silica (amorphous $\mathrm{SiO}_{2}$ beads) as tungsten and template sources, respectively. The as-synthesized tungsten nitride and disulfide ceramics were characterized with conventional laboratory techniques.

\section{Experimental section}

Phosphotungstic acid hydrate $\left(\mathrm{H}_{3} \mathrm{PW}_{12} \mathrm{O}_{40} \cdot \mathrm{xH}_{2} \mathrm{O}\right.$, CAS 12501-23-4, reagent grade) and the Ludox ${ }^{\circledR}$ TM40 colloidal silica (40 wt. \% suspension in $\mathrm{H}_{2} \mathrm{O}$, CAS 7631-86-9) were purchased from Sigma 
Aldrich. Ammonia $\left(\mathrm{NH}_{3}\right)$ and hydrogen sulfide $\left(\mathrm{H}_{2} \mathrm{~S}\right)$ gases were obtained from Air Liquid France. Hydrofluoric acid (40\% in $\mathrm{H}_{2} \mathrm{O}$, CAS 7664-39-3) was purchased from Fischer Scientific. All chemicals were used as-received without any further purification.

\section{Synthesis of the $\left[\mathrm{WO}_{3} / \mathrm{SiO}_{2}\right]$ composite}

The synthesis of the $\left[\mathrm{WO}_{3} / \mathrm{SiO}_{2}\right]$ composite was achieved as follows: $\mathrm{H}_{3} \mathrm{PW}_{12} \mathrm{O}_{40} \cdot \mathrm{xH}_{2} \mathrm{O}(\mathrm{x} \sim 24)$ was dissolved in aqueous dispersions of $22 \mathrm{~nm}$-silica particles (Ludox ${ }^{\circledR} \mathrm{TM} 40$ ) with a [silica spheres/hydrate phosphotungstic acid] weight ratio of about $2 / 3$. The weight ratio was fixed as function of the results discussed in [28]. The mixture was stirred for $1 \mathrm{~h}$, dried in an oven at $80^{\circ} \mathrm{C}$ (Heraeus, VT6025 model, Germany) to evaporate the solvent and then calcined in air at $600^{\circ} \mathrm{C}$ $\left(2^{\circ} \mathrm{C} \cdot \mathrm{min}^{-1}-2 \mathrm{~h}\right)($ Nabertherm GmbH, LT9/12/P320 model, Germany).

$\underline{\text { Synthesis of the tungsten nitride and suphide ceramics }}$

The composites were heat-treated at $750^{\circ} \mathrm{C}$ (3h) (Carbolite Gero, GHA 12/300 model, United Kingdom) while exposed to a flow of $\mathrm{H}_{2} \mathrm{~S}$ or $\mathrm{NH}_{3}$ gas depending of the nature of the desired ceramic; i.e the tungsten disulfide $\left(\mathrm{WS}_{2}\right)$ or the tungsten nitride $\left(\mathrm{W}_{2} \mathrm{~N}\right)$, respectively. The gas flow was fixed at a rate of $1.2 \mathrm{~L} \cdot \mathrm{h}^{-1}$. The resulting $\left[\mathrm{WS}_{2} / \mathrm{SiO}_{2}\right]$ and $\left[\mathrm{W}_{2} \mathrm{~N} / \mathrm{SiO}_{2}\right]$ composites were then treated with a $10 \%$ hydrofluoric acid solution to remove the silica spheres. The powders were recovered by centrifugation, washed several times with distilled water and acetone and finally placed in an oven at $80^{\circ} \mathrm{C}$ for $3 \mathrm{~h}$ hours (Heraeus, VT6025 model, Germany). The grey-black tungsten-based products were denoted $\mathrm{WS}_{2}$ or $\mathrm{W}_{2} \mathrm{~N}$.

Sulfidation and nitridation were also performed in the same experimental conditions on nanostructured $\mathrm{WO}_{3}$ material (after silica template removal) in order to assess the need of maintaining or not the hard template during the reduction processes. These data are reported in the supporting information part.

\section{Characterizations techniques}

The X-Ray powder Diffraction (XRD) was conducted on a D8 Advance diffractometer (Bruker, Germany) using a $\mathrm{Cu} \mathrm{K} \alpha$ radiation $(\lambda=1.54056 \AA)$ with a Lynxeye detector and operating at $40 \mathrm{kV}$ $40 \mathrm{~mA}$. X-ray diffraction patterns were recorded between $2 \theta=10-80^{\circ}$ with a step size of $0.02^{\circ}$ and a step time of $0.1 \mathrm{sec}$. Nitrogen adsorption isotherms were performed at $-196^{\circ} \mathrm{C}$ by means of an 
Accelerated Surface Area and Porosimetry system (ASAP 2020, Micromeritics, USA). Prior to the analyses, the samples were outgassed at $150^{\circ} \mathrm{C}$ under vacuum for $10 \mathrm{~h}$. The specific surface areas $\left(\mathrm{S}_{\mathrm{BET}}\right)$ were calculated according to the Brunauer-Emmett-Teller (BET) method within the 0.05-0.25 relative pressure range. The error on the measurement including the weighting mass is more or less $2 \%$. The pore size distributions were obtained by following the Barret-Joyner-Halenda (BJH) approach applied to the desorption branches. To determine the macroporosity of samples the mercury intrusion porosimetry technique (Autopore IV, Micromeritics, USA) was selected. It is based on the progressive mercury intrusion into the material pores under controlled pressure. The morphologies and structures of the tungsten-based ceramics were investigated from a scanning and transmission electron microscopes such as the Nova NanoSEM 450 and the ARM-200F of the FEI (USA) and JEOL (Japan) companies, respectively.

\section{Results and Discussion}

\subsection{Characterizations of the $\left[\mathrm{SiO}_{2} / \mathrm{WO}_{3}\right]$ composite.}

The $\left[\mathrm{SiO}_{2} / \mathrm{WO}_{3}\right]$ composite prepared following the experimental conditions as-above described was analysed by using the nitrogen adsorption technique and the X-ray powder diffraction (Figure 1). The composite exhibits a type IV isotherm characteristic of the presence of mesopores. Owing to the large relative pressure value where capillary condensations take place, mesopores size could not be determined accurately. Their sizes are centred on $15 \mathrm{~nm}$. The specific surface area and the pore volume were equal to $21 \mathrm{~m}^{2} \cdot \mathrm{g}^{-1}$ and $0.07 \mathrm{~cm}^{3} \cdot \mathrm{g}^{-1}$, respectively. The corresponding diffractogram (Figure 1, insert) shows reflexions of $\mathrm{WO}_{3}$ tungsten (VI) oxide phase (JCPDS No 43-1035, P2 $1 / \mathrm{n}$ space group). No other crystalline phases were detected confirming the amorphous character of $\mathrm{SiO}_{2}$ silica particle template.

Figure 1: Nitrogen adsorption-desorption isotherm (77K) and XRD pattern (insert) of the $\mathrm{SiO}_{2} / \mathrm{WO}_{3}$ composite. 
The $\left[\mathrm{SiO}_{2} / \mathrm{WO}_{3}\right]$ composite was then exposed to a $\mathrm{H}_{2} \mathrm{~S}$ or $\mathrm{NH}_{3}$ atmosphere before the removal of the silica template for the preparation of the targeted tungsten disulfide and ditungsten nitride materials, respectively.

\subsection{Characterizations of the $\mathrm{WS}_{2}$ and $\mathrm{W}_{2} \mathrm{~N}$ materials.}

Figure 2 shows the XRD patterns of the samples synthesized from the sulfidation (Figure 1A) and nitridation (Figure 1B) of the hard templated tungsten (VI) oxide, respectively. About the first pattern, the most intense diffraction peaks can be assigned to (002), (004), (100), (103) (006), (105), (110), (112) and (201) Miller planes which features a hexagonal structure (space group $\mathrm{P}_{3} / \mathrm{mmc}$ ) as related to the $\mathrm{WS}_{2}$ material (JCPDS card No. 08-0237).

Figure 2: XRD patterns of the tungsten disulfide $\mathrm{WS}_{2}(\mathrm{~A})$ and nitride $\mathrm{W}_{2} \mathrm{~N}(\mathrm{~B})$ synthesized from colloidal silica as hard template.

For the sample obtained after nitridation of the tungsten trioxide (Figure 1B), four well-resolved diffraction peaks are observed and can be indexed to the (111), (200), (220) and (311) crystal planes of a cubic structure (space group P-3m1) corresponding to the $\mathrm{W}_{2} \mathrm{~N}$ material (JCPDS card No. 25-1257). The lattice parameter values of each material were calculated according to the well-known Bragg's law and the metric equations. For the tungsten nitride sample, the lattice parameter $a$ was equal to $4.129 \AA$ and for the tungsten disulfide $a$ and $c$ were equal to $3.137 \AA$ and $12.575 \AA$, respectively. The crystallographic data are similar to the tabulated values given by the corresponding cards $\left(a_{\mathrm{W} 2 \mathrm{~N}}=\right.$ $4.126 \AA, \mathrm{a}_{\mathrm{wS} 2}=3.154 \AA, \mathrm{c}_{\mathrm{wS} 2}=12.362 \AA$ ).

The global reaction mechanisms of the tungsten oxide-to-sulfide and the tungsten oxide-to-nitride conversions, from sulphur- and nitrogen-rich gaseous sources, are expressed as follows:

$$
\begin{aligned}
& \mathrm{WO}_{3(\mathrm{~s})}+3 \mathrm{H}_{2} \mathrm{~S}_{(\mathrm{g})} \rightarrow \mathrm{WS}_{2(\mathrm{~s})}+3 \mathrm{H}_{2} \mathrm{O}_{(\mathrm{g})}+\mathrm{S}_{(\mathrm{g})} \\
& 4 \mathrm{WO}_{3(\mathrm{~s})}+8 \mathrm{NH}_{3(\mathrm{~g})} \rightarrow 2 \mathrm{~W}_{2} \mathrm{~N}_{(\mathrm{s})}+12 \mathrm{H}_{2} \mathrm{O}_{(\mathrm{g})}+3 \mathrm{~N}_{2(\mathrm{~g})}
\end{aligned}
$$

A release of gaseous species such as water molecules and sulphur or nitrogen gas occurs. The experimental weight changes of the $\left[\mathrm{WO}_{3} / \mathrm{Ludox}{ }^{\circledR} \mathrm{TM} 40\right]$ composites $\left(48.2 \mathrm{wt} \%\right.$ in $\left.\mathrm{WO}_{3}\right)$ recorded 
before and after heat treatments under $\mathrm{H}_{2} \mathrm{~S}$ or $\mathrm{NH}_{3}$ were compared to the theoretical ones based on the chemical reactions (1) and (2) given previously. Experimentally, weight variations of $+6.6 \%$ and $15.8 \%$ were noted for the sulfidation and nitridation stages, respectively. According to the reactions (1) and (2), the theoretical weights changes (gain or loss) were calculated as equal to $+7.0 \%$ and -17.7 $\%$, respectively, suggesting a partial conversion of the oxide to the sulfide (95\% yield) and to the nitride (90\% yield). This discrepancy could also be related to the experimental uncertainty coupled to a surface oxidation of the non-oxide phases by air (after the synthesis) and in the case of the nitridation to the formation of an amorphous phase, that is not detected by XRD $[13,26]$.

The nitrogen adsorption-desorption isotherms of the tungsten disulfide and nitride samples, prepared with Ludox ${ }^{\circledR}$ TM40 as hard template, are shown in Figure 3A and 3B. Both curves exhibit type-IV profiles with hysteresis loops characteristic of large mesopores, according to the IUPAC classification. The surface properties data; i.e. the specific surfaces areas and cumulated pore volumes, for both prepared materials have been gathered in Table 1. The specific surface areas are high for such type of materials with a value close to $40 \mathrm{~m}^{2} / \mathrm{g}$.

Figure 3: Nitrogen adsorption-desorption isotherms and cumulative pore distribution curves (insert) of tungsten disulfide (A) and tungsten nitride (B) synthesized from colloidal silica as hard template.

Table 1: Surface properties, determined by $\mathrm{N}_{2}$ physisorption $(77 \mathrm{~K})$, of the nanocomposites [W-based ceramic/silica hard template] (1) and the W-based ceramics after the silica template removal (2).* determined from the BJH method for pores below $100 \mathrm{~nm}$.

For both non-oxides tungsten-based samples, a broad pore-size distribution was observed in the large mesopore - small macropore range (insert of Figures 3A and 3B) but caution should be taken regarding the given values since nitrogen physisorption is not accurate for such large pore sizes. This type of porosity corresponds to an interparticular porosity, with an average size around $30-50 \mathrm{~nm}$, that could be related to the templating process. Calculated pore volumes (BJH method) for pores below $100 \mathrm{~nm}$ (insert Figures 3) display values around 0.26 and $0.20 \mathrm{~cm}^{3} / \mathrm{g}$ for $\mathrm{WS}_{2}$ and $\mathrm{W}_{2} \mathrm{~N}$ samples 
respectively. Since spherical silica nanoparticles template removal is supposed to lead to spherical pores shape that does not fit with the cylindrical pore shape considered for pore size calculation by BJH model, direct comparison between pore size and silica particle diameter could not be done. Nevertheless, these values should be in the same order of magnitude [31]. Owing to the large mesopore size observed, complementary analysis was performed by Hg porosimetry.

Figure 4: Cumulative pore volume and differential intrusion versus mean diameter pore size obtained by mercury intrusion porosimetry for $\mathrm{WS}_{2}(\mathrm{~A})$ and $\mathrm{W}_{2} \mathrm{~N}(B)$ samples.

Mercury porosimetry performed on both samples displayed similar features: a broad pore size distribution in the whole pore size range explored $(5 \mathrm{~nm}-10 \mu \mathrm{m})$. Two main contributions of pores can nevertheless be observed for both samples: the first one is centered on $10 \mu \mathrm{m}$ and could be attributed to inter-agglomerate porosity whereas the second is in the mesopore - small macropore range and was ascribed in the interparticular porosity probably templated by the silica spheres. This second porosity is well defined for $\mathrm{W}_{2} \mathrm{~N}$ samples (upward swing around $50 \mathrm{~nm}$ in Figure 4B) whereas it is broadly distributed for $\mathrm{WS}_{2}$ sample (with may be a small maximum around $10 \mathrm{~nm}$ ). Even if nitrogen physisorption is not adapted to accurately measure large mesopores and small macropores, $\mathrm{Hg}$ porosimetry data are in good agreement with $\mathrm{N}_{2}$ adsorption regarding pore volumes measured in their common pore size range (pore size below around $100 \mathrm{~nm}$ ). Indeed, Hg-cumulative pore volume values are 0.24 and $0.21 \mathrm{~cm}^{3} / \mathrm{g}$ to be compared to $\mathrm{N}_{2}$-cumulative pore volume of 0.26 and $0.20 \mathrm{~cm}^{3} / \mathrm{g}$ for $\mathrm{WS}_{2}$ and $\mathrm{W}_{2} \mathrm{~N}$ samples, respectively. The mesoporosity detected by both techniques evidences the templating effect of silica nanospheres.

Figure 5 displays the transmission electron microscope views of the $\mathrm{WS}_{2}$ (Figure $5 \mathrm{~A}$ ) and $\mathrm{W}_{2} \mathrm{~N}$ (Figure 5B) materials.

Figure 5: TEM micrographs of the $\mathrm{WS}_{2}(\mathrm{~A})$ and $\mathrm{W}_{2} \mathrm{~N}(\mathrm{~B})$ prepared from colloidal silica template. 
The low magnifications pictures of both materials exhibit powders constituted of agglomerated particles with nanosized dimensions. For the tungsten disulfide (Figure 5A), the particles exhibit a typical layered morphology as reported in the literature $[17,24,25]$ while particles with a coalesced sphere-shape morphology, are observed for the tungsten heminitride material having a cubic structure (Figure 5B). These different aspect ratios related to isotropic and anisotropic crystal growths could explained why only the $\mathrm{W}_{2} \mathrm{~N}$ sample succeed to maintain the templated pore size in the mesoporous range (population of pores around $50 \mathrm{~nm}$, evidenced by $\mathrm{Hg}$ porosimetry in Figure $4 \mathrm{~B}$ ) - while a broader pore size distribution is encountered in the case of $\mathrm{WS}_{2}$ (Figure 4A). The high-resolution TEM images (insert of each low magnification picture) clearly show that the particles are well-crystallized since crystallographic planes are noticed. Moreover, from these images, an approximate particle size may be determined; ranging from 20 to $30 \mathrm{~nm}$ for the tungsten nitride and $5-10 \mathrm{~nm}$ and $40-50 \mathrm{~nm}$ (thickness and length), for the tungsten sulfide material.

Additional characterizations of the $\mathrm{WS}_{2}$ and the $\mathrm{W}_{2} \mathrm{~N}$ were provided by scanning electron microscopy. Representative micrographs are shown within Figure 6A and 6B. The disulfide and nitride samples are featured by highly agglomerated nanoparticles exhibiting a quasi-spherical morphology.

Figure 6: SEM views of the $\mathrm{WS}_{2}(\mathrm{~A})$ and $\mathrm{W}_{2} \mathrm{~N}$ (B) prepared from colloidal silica template.

From a meticulous observation, the particle size ranges from 20 to $30 \mathrm{~nm}$ which is consistent with the size of the $\mathrm{WO}_{3}$ precursor material [28] implying that no significant structural modification occurred during the oxide-to-sulfide and oxide-to-nitride conversions. This observation can be largely attributed to the presence of the siliceous hard template during the reductive treatment under hydrogen sulfide or ammonia environments of the $\left[\mathrm{WO}_{3} / \mathrm{SiO}_{2}\right]$ nanocomposite. Indeed, sulfidation or nitridation of $\mathrm{WO}_{3}$ material (obtained after the template removal of the $\left[\mathrm{WO}_{3} / \mathrm{SiO}_{2}\right]$ nanocomposite) led to bigger particles (> $50 \mathrm{~nm}$ ) which appeared more sintered (Figure 7). The specific surfaces areas of the $\mathrm{WS}_{2}$ and $\mathrm{W}_{2} \mathrm{~N}$ samples were calculated as close to 16 and $18 \mathrm{~m}^{2} \cdot \mathrm{g}^{-1}$, respectively, which are nearly 2-2.5 times lower than the values obtained for the sulfide- and nitrogen-based samples synthesized from the sulfidation and nitridation of the $\left[\mathrm{WO}_{3} / \mathrm{SiO}_{2}\right]$ nanocomposites. The silica template causes a 
confinement effect of the oxide matter during the treatment under hydrogen sulfide or ammonia thus limiting the growth or the sintering of the resulting particles.

Figure 7: TEM views of the $\mathrm{WS}_{2}(\mathrm{~A})$ and $\mathrm{W}_{2} \mathrm{~N}(\mathrm{~B})$ materials prepared from sulfidation and nitridation of $\mathrm{WO}_{3}$ material free of Ludox ${ }^{\circledR T M} 40$ template.

By comparison with the literature, our $\mathrm{WS}_{2}$ and $\mathrm{W}_{2} \mathrm{~N}$ samples may be ranked as interesting materials regarding their specific surface areas (around $40 \mathrm{~m}^{2} / \mathrm{g}$ ) and their process based on an economic and commercially available hard-template. For instance, tungsten disulfide was elaborated by heat treatment under reductive atmosphere either after a mechanical ball-milling step or by impregnation method (under vacuum or not) of three-dimensional ordered mesoporous silicas (hard templates) of SBA-15 or KIT-6 mesostructures. If in the first case, large scale fabrication can be considered, the specific surface appears limited $\left(10.5 \mathrm{~m}^{2} / \mathrm{g}[14]\right)$ whereas it is no more the case regarding the second process that offers surface areas up to $110-120 \mathrm{~m}^{2} / \mathrm{g}[6,25]$ with limited amount of material. Moreover, these two approaches are more energy- and time-consuming (ball-milling of 24h, silica template synthesis) than our investigated route. Regarding the tungsten nitride material, the amplitude of variation of the specific surface area value is narrower since values of $17 \mathrm{~m}^{2} / \mathrm{g}$ to $79 \mathrm{~m}^{2} / \mathrm{g}$ were reported $[9,19,26,7,20,13,18,22]$. The nitrogen-based ceramic materials with the highest surface properties are essentially prepared from tungstic acid $\left(\mathrm{WO}_{3} \cdot \mathrm{xH}_{2} \mathrm{O}\right)$ as tungsten precursor. This molecule is non soluble in aqueous medium that may be a potential drawback for the preparation of nitrides materials with well-defined morphologies (2D-, 3D-structures) by the hard-template route whereas for our process, the phosphotungstic acid is highly soluble in water $(2 \mathrm{~kg} / \mathrm{L})$.

\section{Conclusions}

Meso- and macroporous tungsten disulfide $\left(\mathrm{WS}_{2}\right)$ and hemitungsten nitride $\left(\mathrm{W}_{2} \mathrm{~N}\right)$ powders were successfully synthesized by means of tungsten (VI) oxide as tungsten source and colloidal silica acting as hard template. The surface properties of the $\mathrm{WS}_{2}$ and $\mathrm{W}_{2} \mathrm{~N}$ materials (specific surfaces areas $\sim 40$

$\mathrm{m}^{2} \cdot \mathrm{g}^{-1}$, pore volume of around $0.2 \mathrm{~cm}^{3} \cdot \mathrm{g}^{-1}$ for pores below $100 \mathrm{~nm}$ ) are comparable to the values given 
in the literature where non commercial templates have been used. To sum up, colloidal silicas may be a competitive solution for the development of mesoporous sulfides and nitrides ceramics since the template is easily available in large amounts, marketed in different particle sizes and more economic than the classical ordered mesoporous silica matrices (M41S, SBA, FSU...), conventionally used for similar research.

\section{References}

[1] S.T. Oyama, The Chemistry of Transition metal Carbides and Nitrides, first ed., Chapman-Hall, London, 1996.

[2] Handbook of Chemistry and Physics, $68^{\text {th }}$ Edition CRC Press, 1987-1988.

[3] L. Rapoport, V. Leshchinsky,Y. Volovik, M. Lvovsky, O. Nepomnyashchy, Y. Feldman et al., Modification of contact surfaces by fullerene-like solid lubricant nanoparticles, Surf. Coat. Technol. 163-167 (2003) 405-412.

[4] S. Dong, X. Chen, X. Zhang, G. Cui, Nanostructured transition metal nitrides for energy storage and fuel cells, Coord. Chem. Rev. 257 (2013) 1946- 1956.

[5] H. Zhong, H. Zhang, Y. Liang, J. Zhang, M. Wang, X. Wang, A novel non-noble electrocatalyst for oxygen reduction in proton exchange membrane fuel cells, J. Power Sources, 164 (2007) 572-577.

[6] H. Liu, D. Su, G. Wang, S.Z. Qiao, An ordered mesoporous $\mathrm{WS}_{2}$ anode material with superior electrochemical performance for lithium ion batteries , J. Mater. Chem. 22 (2012) 17437-17440.

[7] R.C.V. McGee, S.K. Bej, L.T. Thompson, Basic properties of molybdenum and tungsten nitride catalysts? Appl. Catal. A. 284 (2005) 139-146.

[8] J. Chen, S.L. Li, Q. Xu, K. Tanaka, Synthesis of open-ended $\mathrm{MoS}_{2}$ nanotubes and the application as the catalyst of methanation, Chem. Commun. 16 (2002) 1722-1723.

[9] C. Shi, X.F. Yang, A.M. Zhu, C.T. Au, Catalytic activities of tungsten nitride for NO dissociation and reduction with hydrogen, Catal. Today 93-95 (2004) 819-826.

[10] A. Kafizas, C.J. Carmalt, I.P. Parkin, CVD and precursor chemistry of transition metal nitrides, Coord. Chem. Rev. 257 (2013) 2073-2119.

[11] Y.Q. Zhu, W.K. Hsu, H. Terrones, N. Grobert, B.H. Chang, M. Terrones, B.Q. Wei, H.W. Kroto, D.R.M. Walton, C.B. Boothroyd, I. Kinloch, G.Z. Chen, A.H. Windle, D.J. Fray, Morphology, structure and growth of $\mathrm{WS}_{2}$ nanotubes, J. Mater. Chem. 10 (2000) 2570-2577.

[12] R. Sen, A. Govindaraj, K. Suenaga, S. Suzuki, H. Kataura, S. Iijita, Y. Achiba, Encapsulated and hollow closed-cage structures of $\mathrm{WS}_{2}$ and $\mathrm{MoS}_{2}$ prepared by laser ablation at $450-1050^{\circ} \mathrm{C}$, Chem. Phys. Lett. 340 (2001) 242-248.

[13] C. Giordano, M. Antonietti, Synthesis of crystalline metal nitride and metal carbide nanostructures by solgel chemistry, Nano Today 6 (2011) 366-380.

[14] Z. Wu, B. Fang, A. Bonakdarpour, A. Sun, D. P. Wilkinson, D. Wang, $\mathrm{WS}_{2}$ nanosheets as a highly efficient electrocatalyst for hydrogen evolution reaction, Appl. Catal. B 125 (2012) 59 - 66. 
[15] Z. Wu, Dezhi Wang, X. Zan, A. Sun, Synthesis of $\mathrm{WS}_{2}$ nanosheets by a novel mechanical activation method, Mater. Lett. 64 (2010) 856-858.

[16] K. Shiva, H. S. S. Ramakrishna Matte, H. B. Rajendra, A. J. Bhattacharyya, C. N. R. Rao, Employing synergistic interactions between few-layer $\mathrm{WS}_{2}$ and reduced graphene oxide to improve lithium storage, cyclability and rate capability of Li-ion batteries, Nano Energy 2 (2013) 787-793.

[17] C. Feng, L. Huang, Z. Guo, H. Liu, Synthesis of tungsten disulfide $\left(\mathrm{WS}_{2}\right)$ nanoflakes for lithium ion battery application, Electrochem. Commun. 9 (2007) 119-122.

[18] P. Bai, W. Xing, Z. Yan, Synthesis and characterization of mesostructured tungsten nitride by using tungstic acid as the precursor, J. Porous Mat. 13 (2006) 173-180.

[19] L. Villaseca, B. Moreno, I. Lorite, J.R. Jurado, E. Chinarro, Synthesis and characterization of tungsten nitride $\left(\mathrm{W}_{2} \mathrm{~N}\right)$ from $\mathrm{WO}_{3}$ and $\mathrm{H}_{2} \mathrm{WO}_{4}$ to be used in the electrode of electrochemical devices, Ceram. Inter. 41 (2015) 4282-4288.

[20] A.R. Ko, S.B. Han, Y.W. Lee, K.W. Park, Template-free synthesis and characterization of mesoporous tungsten nitride nanoplates , Phys. Chem. Chem. Phys. 13 (2011) 12705-12707.

[21] V. Chakrapani, J. Thangala, M.K. Sunkara, $\mathrm{WO}_{3}$ and $\mathrm{W}_{2} \mathrm{~N}$ nanowire arrays for photoelectrochemical hydrogen production, Int. J. Hydrogen Energy 34 (2009) 9050-9059.

[22] J.H. Kim, K.L. Kim, A study of preparation of tungsten nitride catalysts with high surface area, Appl. Catal. A 181 (1999) 103-111.

[17] V. An, F. Bozheyev, F. Richecoeur, Y. Irtegov, Synthesis and characterization of nanolamellar tungsten and molybdenum disulfides, Mater. Lett. 65 (2011) 2381-2383.

[23] S. Sun, Z. Zou, G. Min, Synthesis of tungsten disulfide nanotubes from different precursor, Mater. Chem. Phys. 114 (2009) 884-888.

[24] S. Sun, Z. Li, X. Chang, Synthesis and structural characterization of tungsten disulfide nanomaterials, Mater. Lett. 65 (2011) 3164-3166.

[25] Y. Shi, Y. Y. Wan, R. Liu, B. Tu, D. Zhao, Synthesis of Highly Ordered Mesoporous Crystalline WS Wnd $\mathrm{MoS}_{2}$ via a High-Temperature Reductive Sulfuration Route, J. Am. Chem. Soc. 129 (2007) 9522-9531.

[26] S. Meyer, H. Beyer, K. Kohler, A.H. Jensen, E. Christensen, N.J. Bjerrum, Space-confined preparation of high surface area tungsten oxide and tungsten nitride inside the pores of mesoporous silica SBA-15, Micro. Meso. Mater. 211 (2015) 147-151.

[27] P. Gibot, L. Vidal, Original synthesis of chromium (III) oxide nanoparticles, J. Eur. Ceram. Soc. 30 (2010) 911-915

[28] P. Gibot, M. Comet, L. Vidal, F. Moitrier, F. Lacroix, Y. Suma, F. Schnell, D. Spitzer, Synthesis of $\mathrm{WO}_{3}$ nanoparticles for superthermites by the template method from silica spheres, Solid State Sci. 13 (2011) 908-914

[29] F. Goettmann, A. Fischer, M. Antonietti, A. Thomas, Chemical synthesis of mesoporous carbon nitrides using hard templates and their use as a metal-free catalyst for Friedel-Crafts reaction of benzene, Angew. Chem. Int. Ed. 45 (2006) 4467-4471.

[30] G. An, C. Xiong, C. Lu, Z. Chen, Direct synthesis of porous molybdenum disulfide materials using silica sol as the template, J. Porous Mater. 18 (2011) 673-676.

[31] J.V. Rocha, D. Barrera, K. Sapag, Improvement in the pore size distribution for ordered mesoporous materials with cylindrical and spherical pores using the Kelvin equation, Top. Catal. 54 (2011) 121-134. 
Table caption

Table 1: Surface properties, determined by $\mathrm{N}_{2}$ physisorption (77K), of the nanocomposites [W-based ceramic/silica hard template] (1) and the $\mathrm{W}$-based ceramics after the silica template removal (2).* determined from the BJH method for pores below $100 \mathrm{~nm}$. 


\begin{tabular}{|c|c|c|}
\hline Ceramic & $\begin{array}{c}\text { Specific surface area } \\
\left(\mathrm{m}^{2} / \mathrm{g}\right)\end{array}$ & $\begin{array}{c}\text { Pore volume* } \\
\left(\mathrm{cm}^{3} / \mathrm{g}\right)\end{array}$ \\
\hline $\mathrm{W}_{2} \mathrm{~N}_{-} \mathrm{TM} 40^{(1)}$ & 19 & 0.05 \\
\hline $\mathrm{W}_{2} \mathrm{~N}^{(2)}$ & 37 & 0.20 \\
\hline $\mathrm{WS}_{2 \_} \mathrm{TM}_{40}{ }^{(1)}$ & 20 & 0.06 \\
\hline $\mathrm{WS}_{2}{ }^{(2)}$ & 38 & 0.26 \\
\hline
\end{tabular}




\section{Figure captions}

Figure 1: Nitrogen adsorption-desorption isotherm (77K) and XRD pattern (in insert) of the $\left[\mathrm{SiO}_{2} / \mathrm{WO}_{3}\right]$ composite.

Figure 2: XRD patterns of the tungsten disulfide $\mathrm{WS}_{2}(\mathrm{~A})$ and nitride $\mathrm{W}_{2} \mathrm{~N}(\mathrm{~B})$ synthesized from colloidal silica as hard template.

Figure 3: Nitrogen adsorption-desorption isotherms and cumulative pore size distribution curves (insert) of tungsten disulfide (A) and tungsten nitride (B) synthesized from colloidal silica as hard template.

Figure 4: Cumulative pore volume and differential intrusion versus mean diameter pore size obtained by mercury intrusion porosimetry for $\mathrm{WS}_{2}(A)$ and $\mathrm{W}_{2} \mathrm{~N}(B)$ samples.

Figure 5: TEM views of the $\mathrm{WS}_{2}(\mathrm{~A})$ and $\mathrm{W}_{2} \mathrm{~N}(\mathrm{~B})$ prepared from colloidal silica template.

Figure 6: SEM views of the $\mathrm{WS}_{2}(\mathrm{~A})$ and $\mathrm{W}_{2} \mathrm{~N}$ (B) prepared from colloidal silica template.

Figure 7: TEM views of the $\mathrm{WS}_{2}(\mathrm{~A})$ and $\mathrm{W}_{2} \mathrm{~N}(\mathrm{~B})$ materials prepared from sulfidation and nitridation of $\mathrm{WO}_{3}$ material free of Ludox $\circledast \mathrm{TM} 40$ template. 


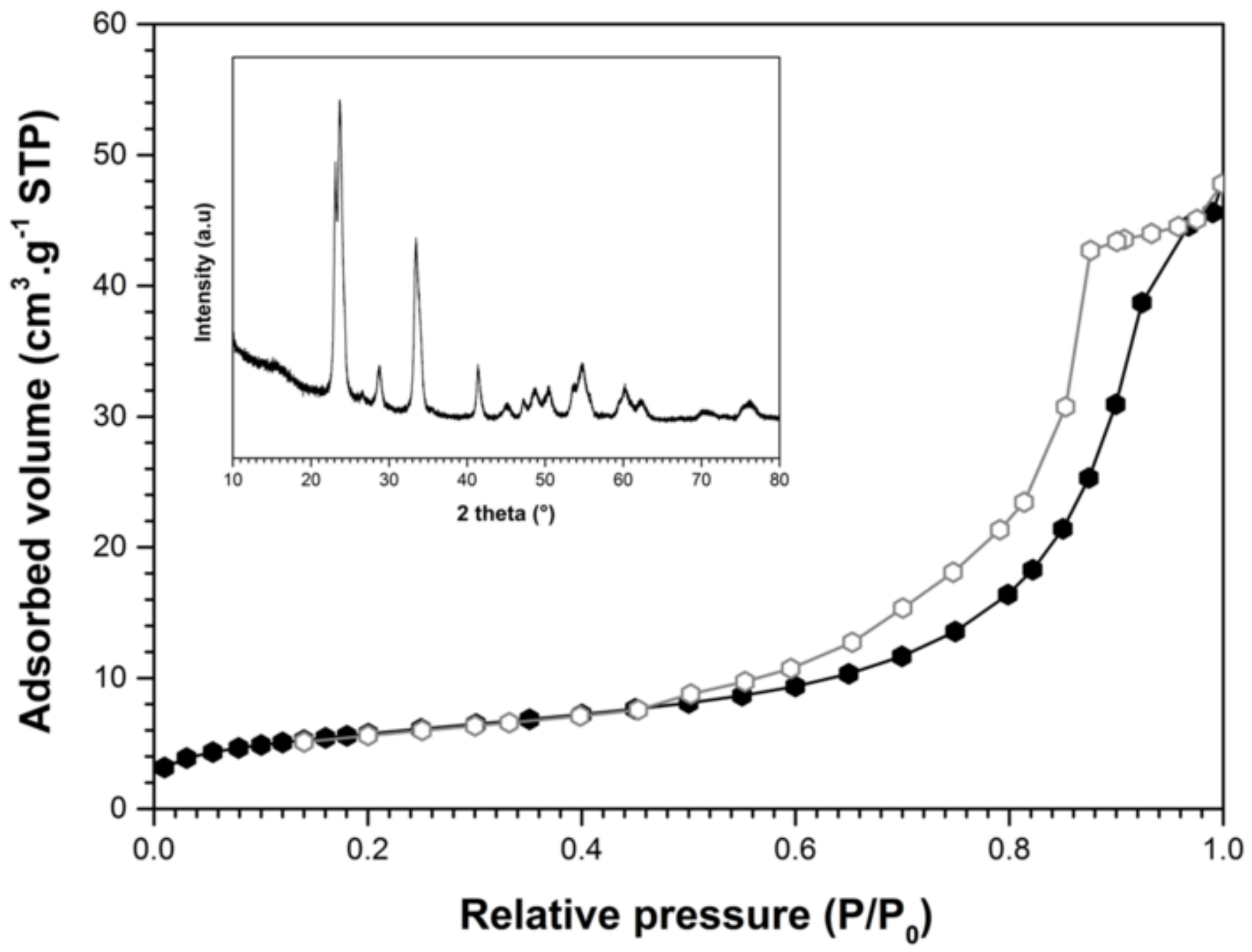




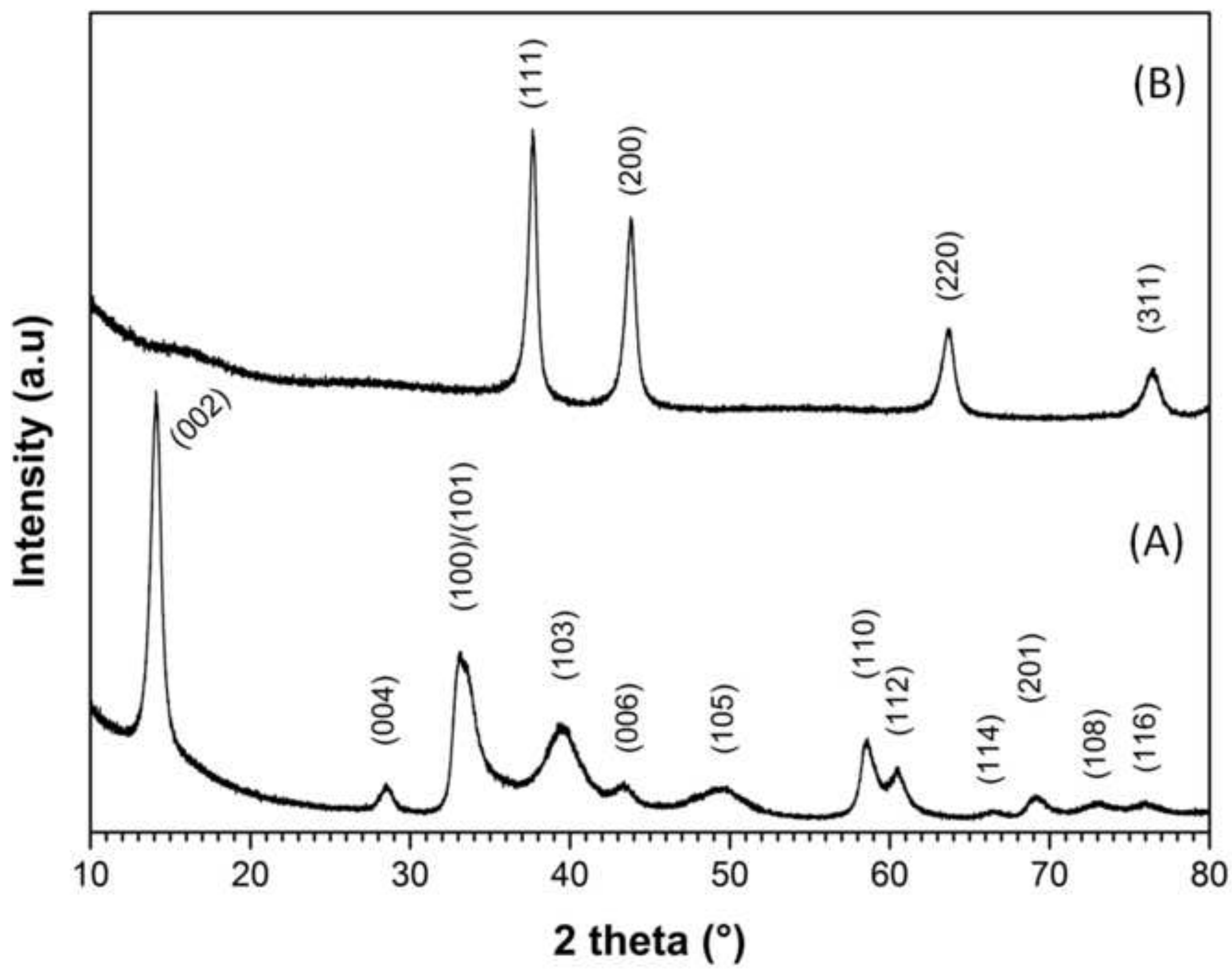




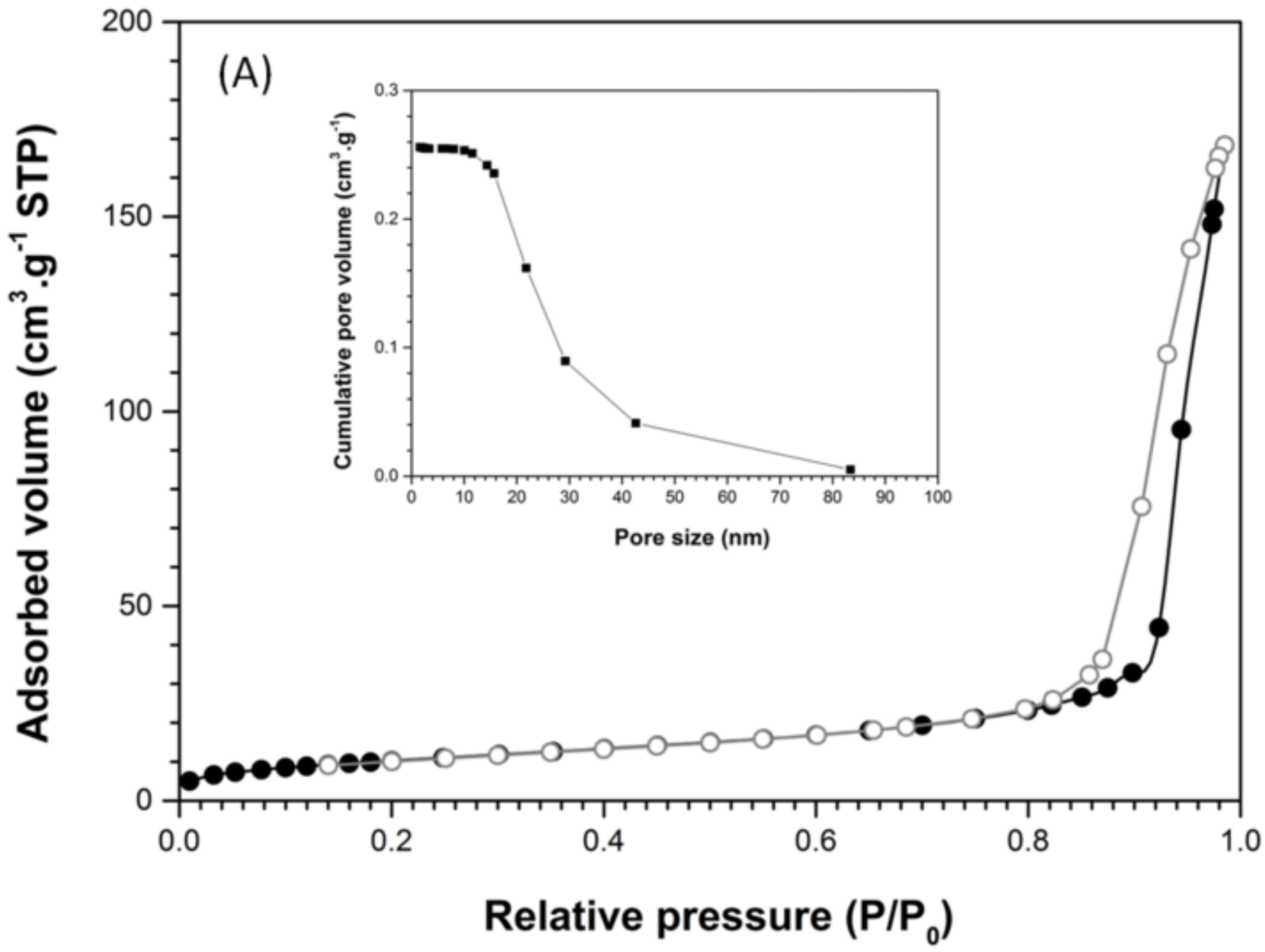




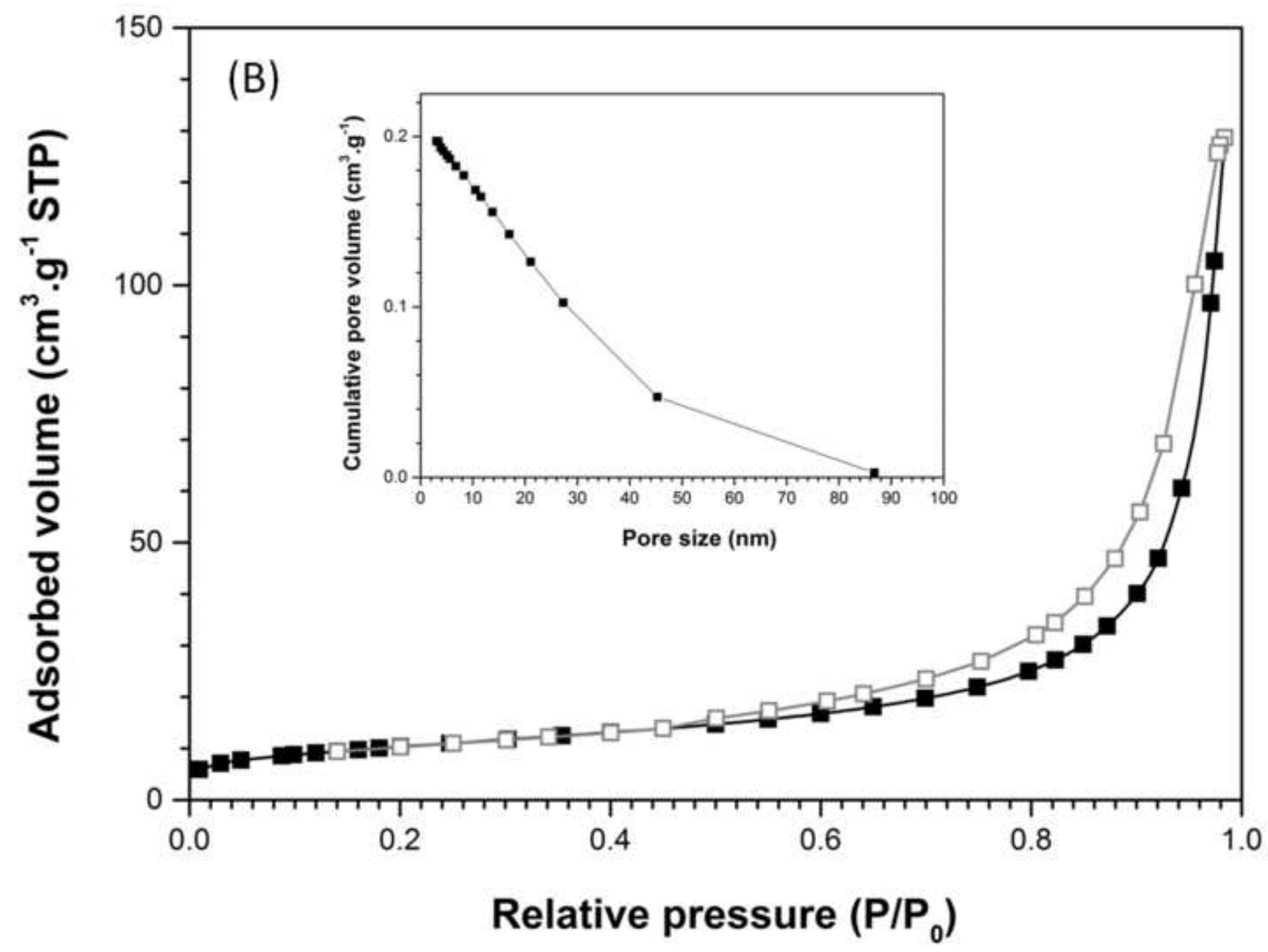


Figure $4 \mathrm{~A}$
Click here to download high resolution image

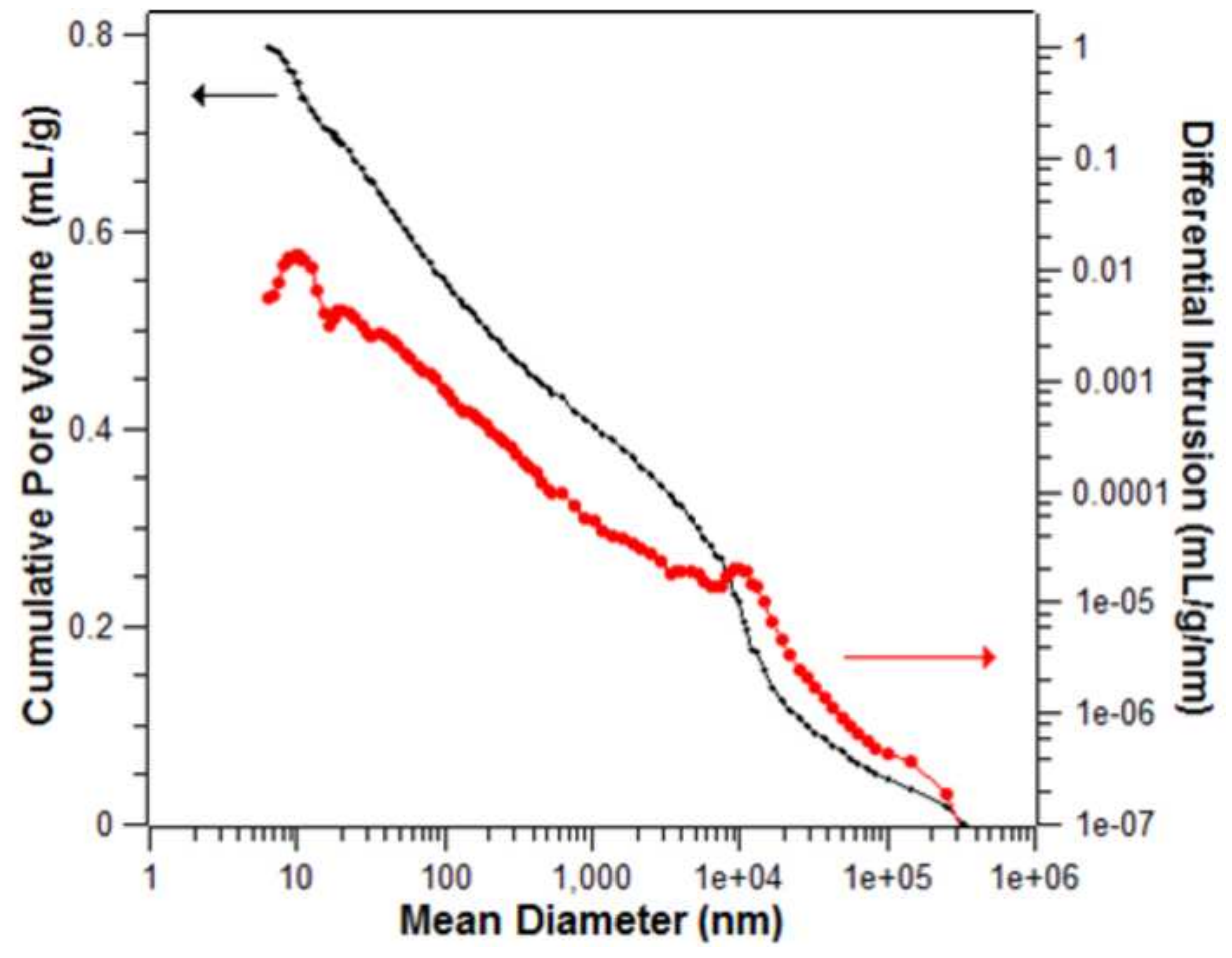




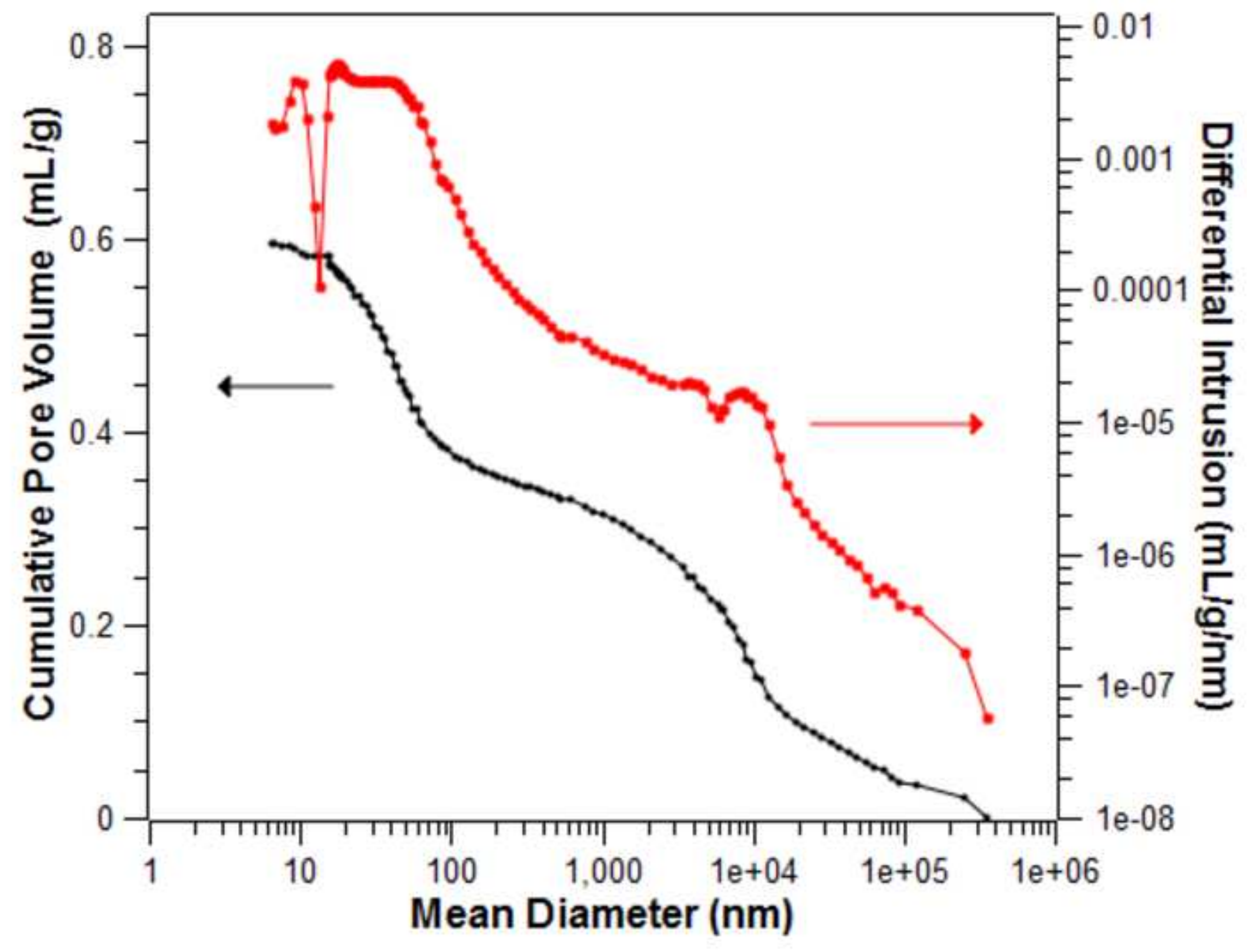


Click here to download high resolution image

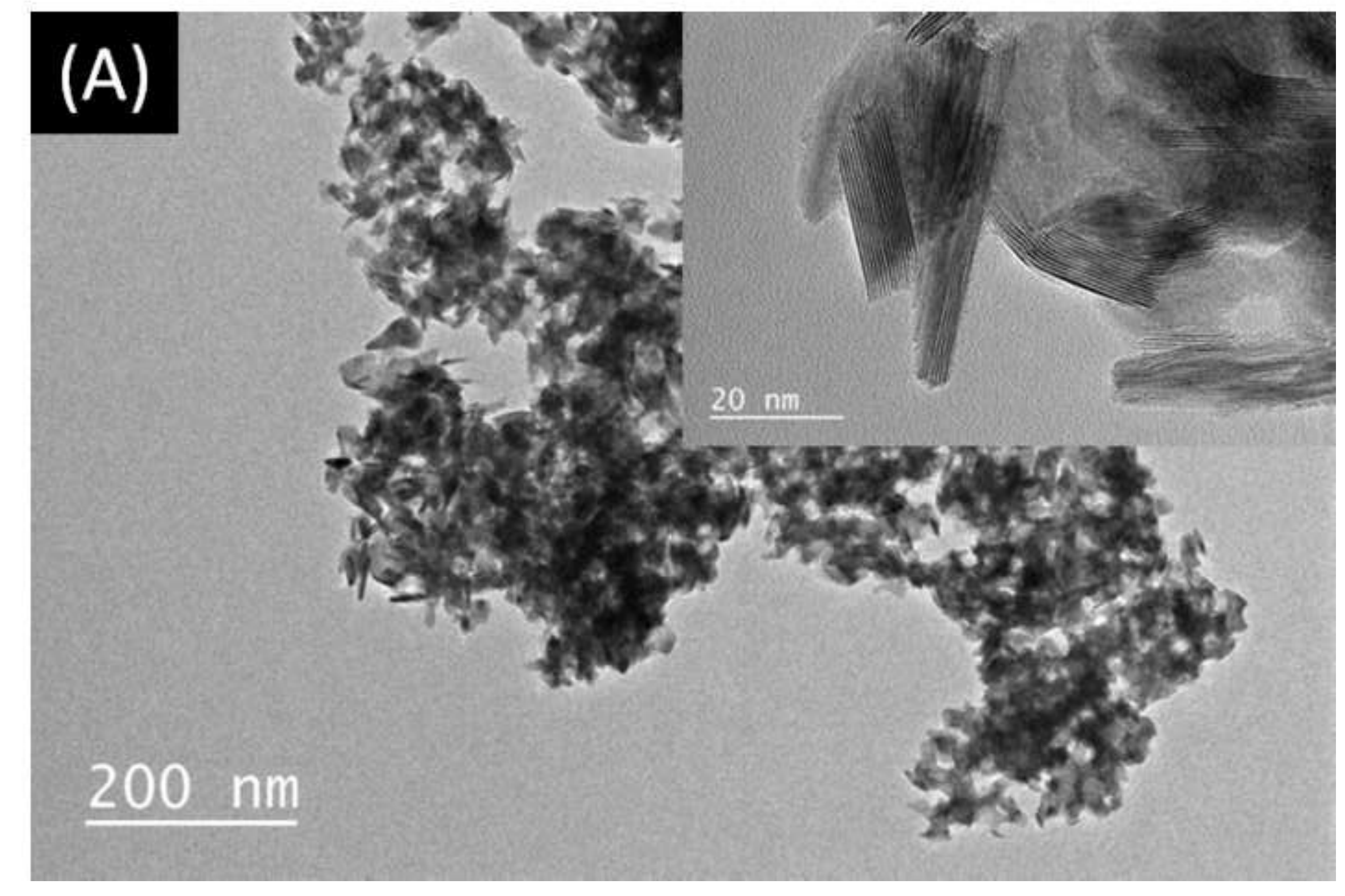

Click here to download high resolution image 

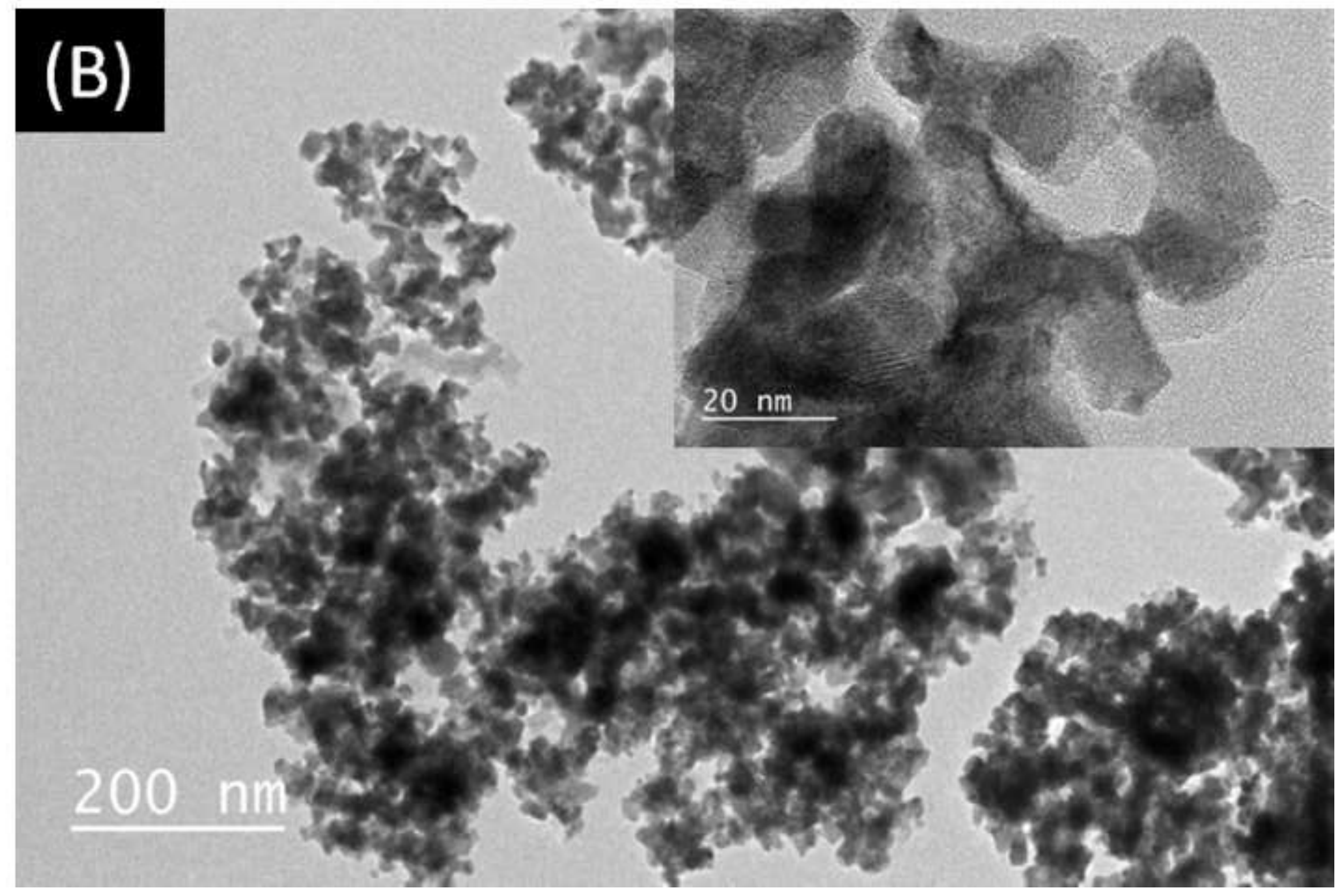

200 nithes
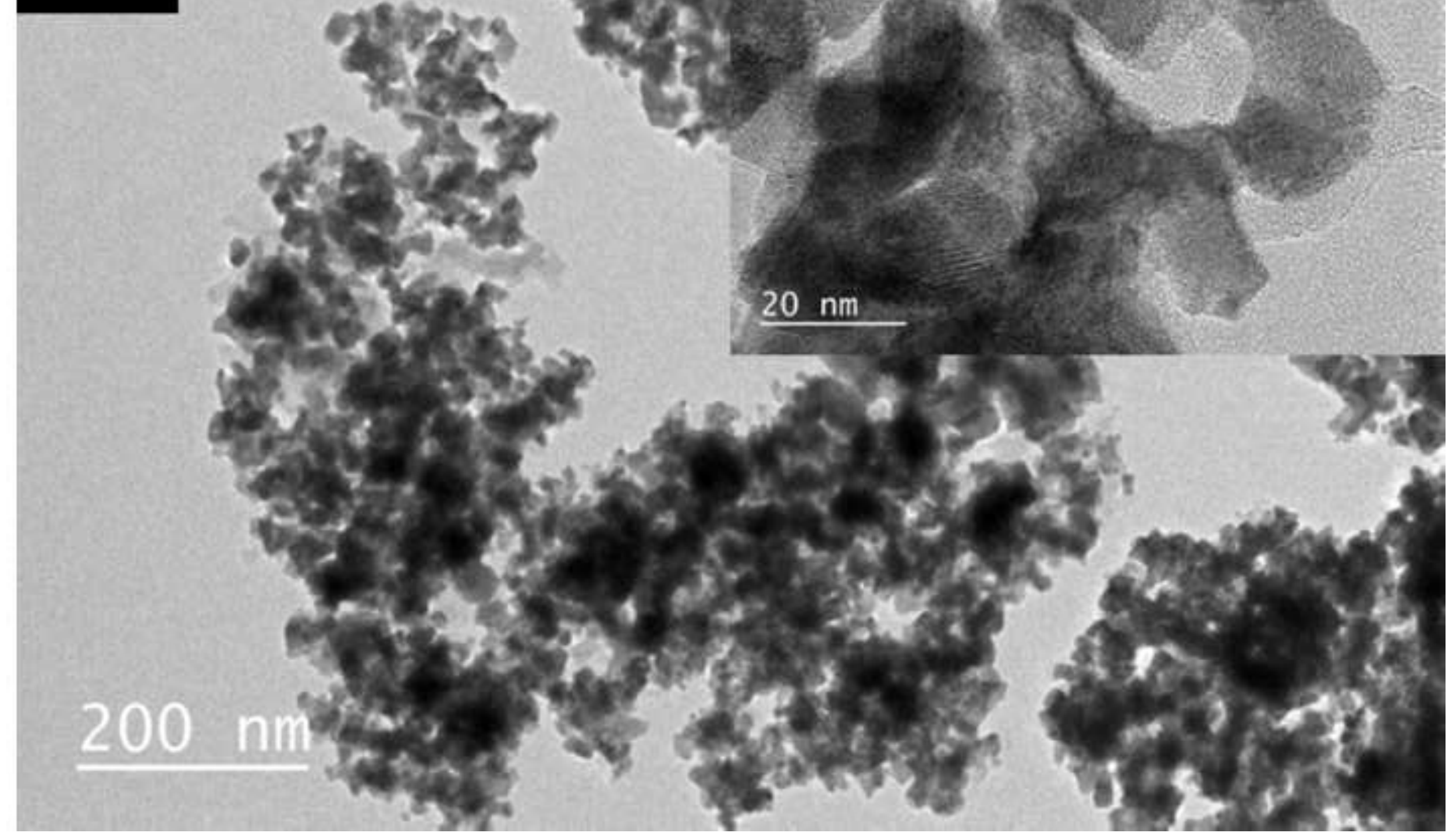
Click here to download high resolution image

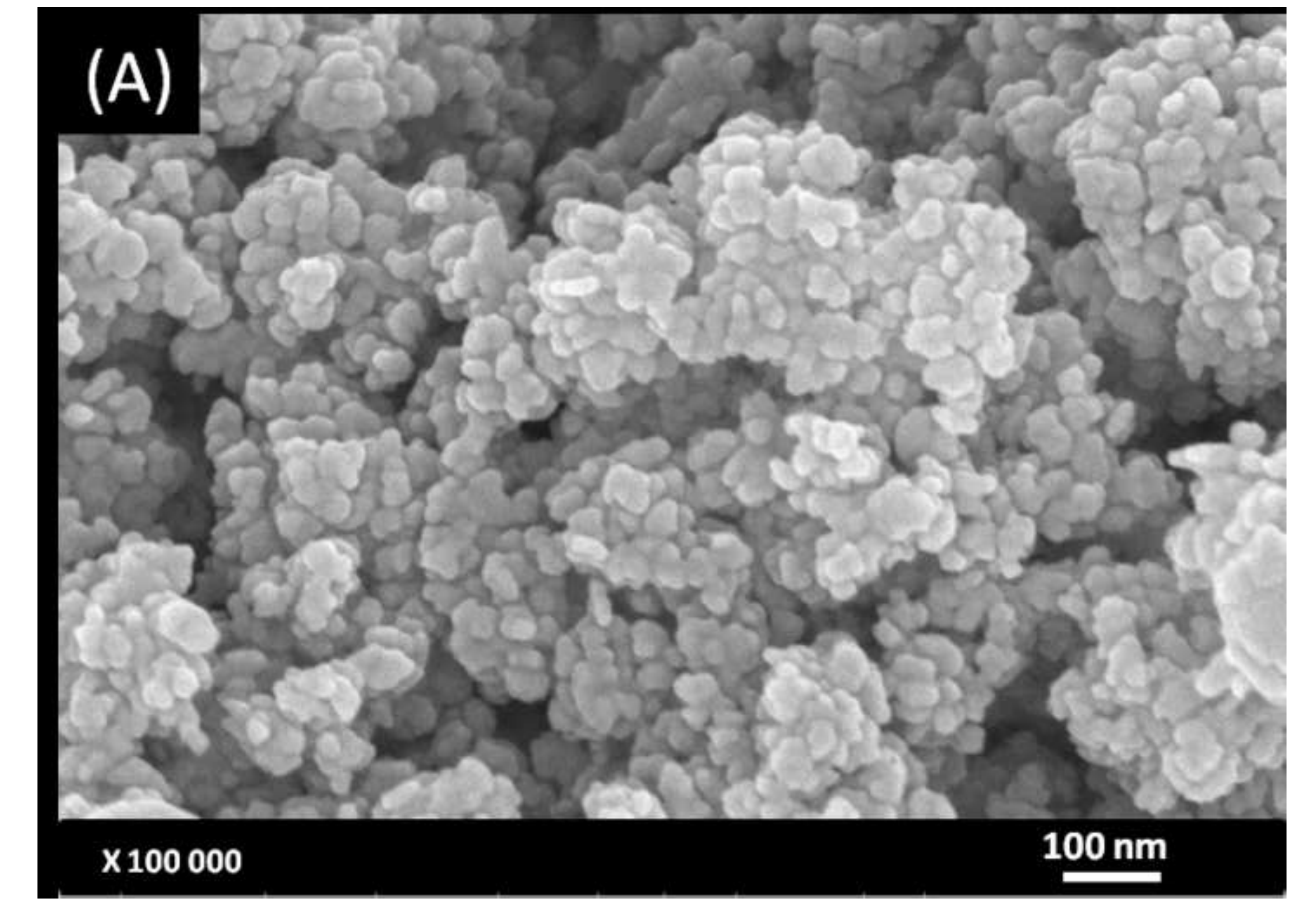

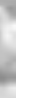

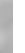

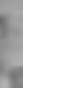

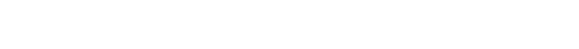


Click here to download high resolution image

\section{(A)}

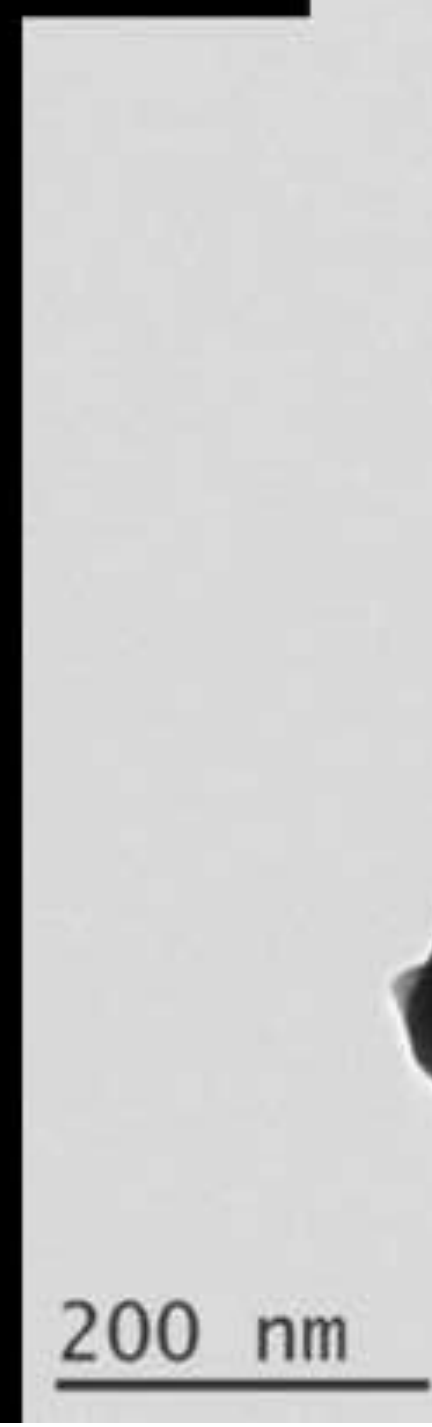

$20 . \mathrm{nm}$
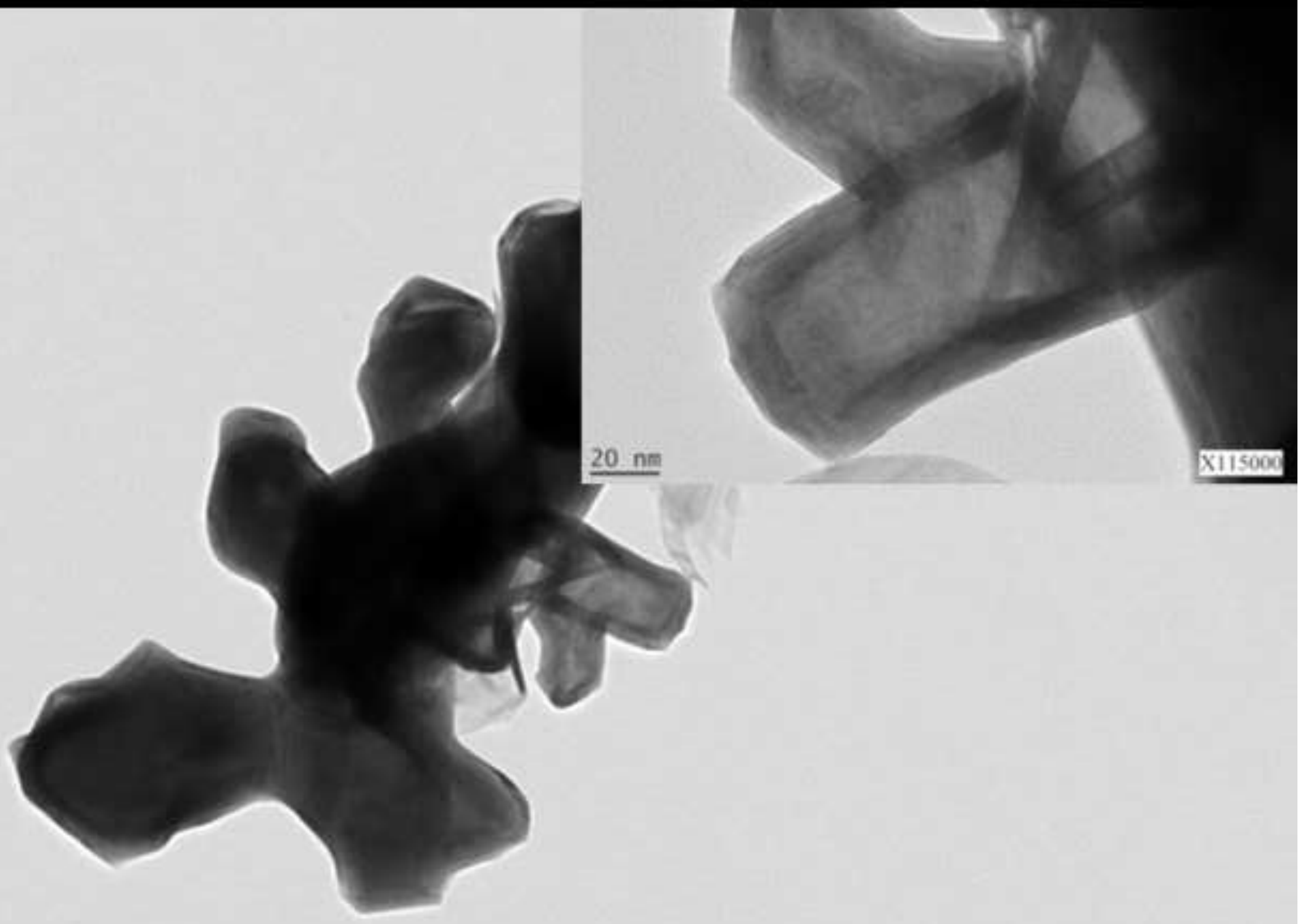

X20000 
